
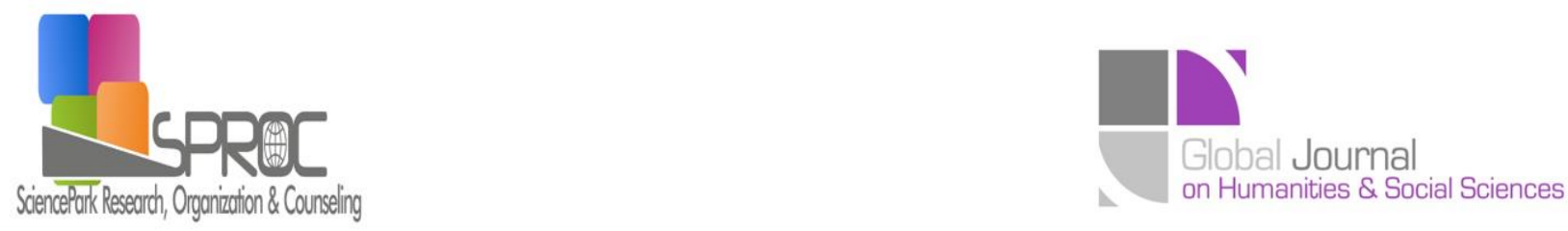

\title{
Development of a methodology for assessing the tourism sector competitiveness at the national level
}

Svetlana Ignatjeva *, Naila Musayeva,

Suggested Citation:

Abstract 
1. Introduction

2. Research in the area of tourism competitiveness index components 


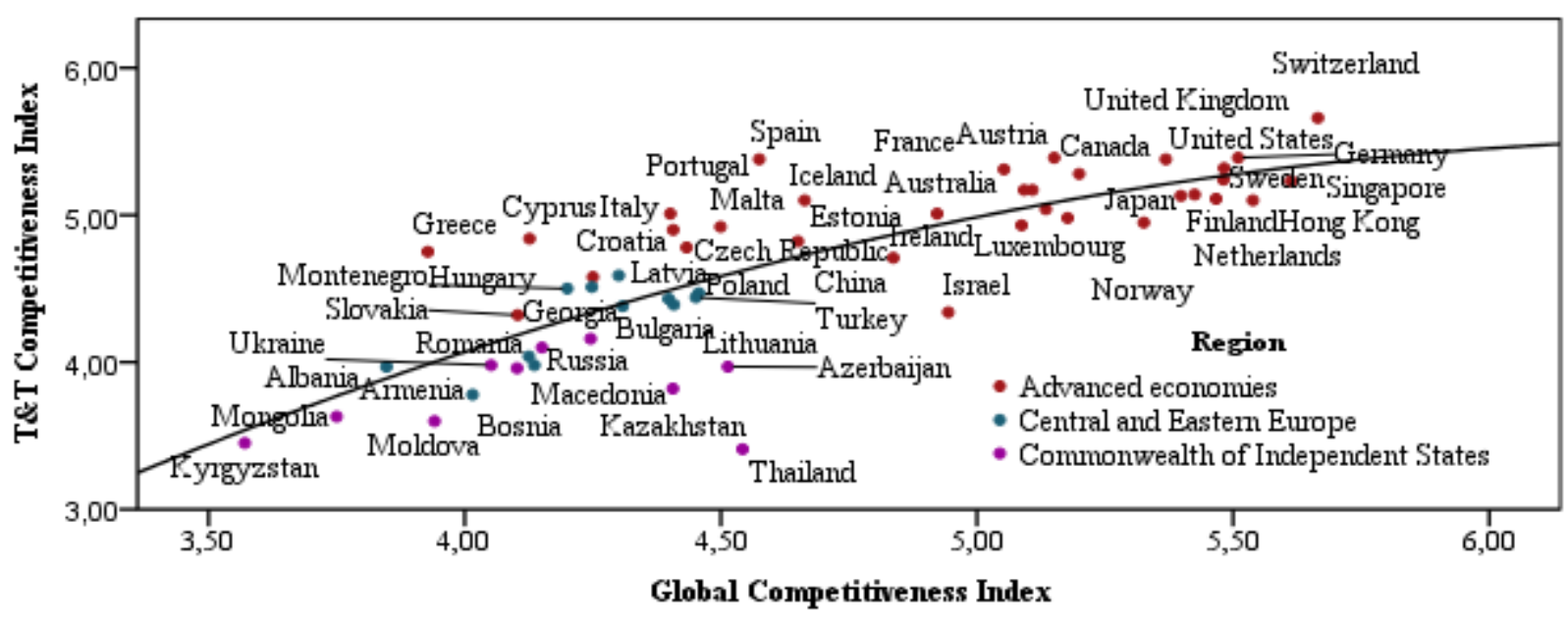





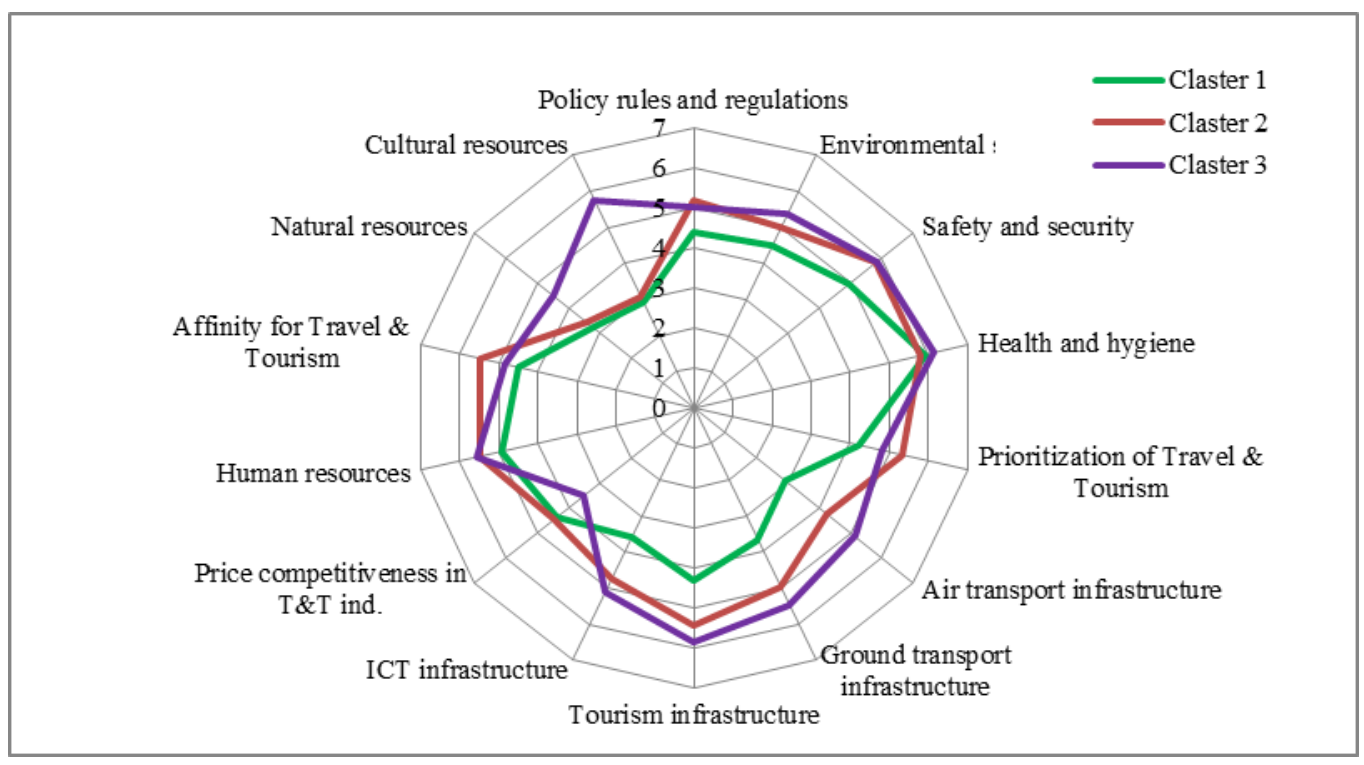


3. Conclusions 
References 